\title{
Social acceptance of renewable energy innovation: An introduction to the concept
}

\author{
Rolf Wüstenhagen $^{\mathrm{a}, *}$, Maarten Wolsink ${ }^{\mathrm{b}}$, Mary Jean Bürer ${ }^{\mathrm{a}}$ \\ ${ }^{a}$ Institute for Economy and the Environment, University of St. Gallen, Tigerbergstrasse 2, CH-9000 St. Gallen, Switzerland \\ ${ }^{\mathrm{b}}$ Department of Geography, Planning and International Development Studies, University of Amsterdam, Nieuwe Prinsengracht 130, \\ NL-1018 VZ Amsterdam, The Netherlands
}

Available online 26 February 2007

\begin{abstract}
This paper introduces the special issue on Social Acceptance of Renewable Energy Innovation. It is a collection of best papers presented at an international research conference held in Tramelan (Switzerland) in February 2006. While there are ambitious government targets to increase the share of renewable energy in many countries, it is increasingly recognized that social acceptance may be a constraining factor in achieving this target. This is particularly apparent in the case of wind energy, which has become a subject of contested debates in several countries largely due to its visual impact on landscapes. This paper introduces three dimensions of social acceptance, namely socio-political, community and market acceptance. Factors influencing socio-political and community acceptance are increasingly recognized as being important for understanding the apparent contradictions between general public support for renewable energy innovation and the difficult realization of specific projects. The third dimension, market acceptance, has received less attention so far and provides opportunities for further research, particularly from management scholars.
\end{abstract}

(C) 2006 Published by Elsevier Ltd.

Keywords: Social acceptance; Wind energy; Diffusion of innovation

\section{Introduction}

Increasing the share of renewable energy is high on the policy agenda in countries around the world. Several governments have set ambitious targets and have started to implement support schemes aimed at facilitating market implementation. The degree to which these policies have been successful varies between countries, but wind energy stands out with the most impressive growth in some countries. As wind turbines are spreading, however, it has been increasingly recognized that there is one factor that can potentially be a powerful barrier to the achievement of renewable energy targets: social acceptance. In Germany, the country with the largest number of installed wind turbines worldwide, the media has picked up on the theme of local resistance to new wind energy projects. Countries that are only at the beginning of the diffusion curve, such as the UK, the Netherlands, Switzerland or France, are

\footnotetext{
${ }^{*}$ Corresponding author. Tel.: +41712242587.

E-mail address: rolf.wuestenhagen@unisg.ch (R. Wüstenhagen).
}

also facing vivid debates on local and sometimes national levels. While debates on social acceptance are not totally new to the energy sector-just think of contested siting decisions for nuclear power plants, nuclear waste storage facilities, or large hydropower dams - this issue needs to be urgently addressed if policies are to be implemented successfully.

Social acceptance as a part of renewable energy technology implementation has largely been neglected in the eighties when the policy programs started. Most developers, including energy companies, authorities, and private local investors thought that implementation was not a problem, because the first surveys on the public acceptance of renewables, in particular wind power, revealed very high levels of support for the technology. However, the first investigations that looked beyond this simple observation tried to further elaborate the conditions that determine the effective support that applications of wind power would get. At the time, such issues were usually perceived as residual questions simply called 'nontechnical' factors (Carlman, 1982). These studies already 
showed that neither public support, nor support from crucial stakeholders at varying scale-levels could be taken for granted. Carlman was the first scholar that defined the problem of social acceptance for wind power and she immediately went beyond the mere study of public opinion. She started by stating that siting wind turbines was "also a matter of public, political, and regulatory acceptance", and she carried out a study on the acceptance of wind power among decision makers (Carlman, 1984, p. 339). Her studies suggested that there were several constraints for social acceptance, and soon in the eighties other academics joined her in defining and analyzing the problematic issues for implementation (Bosley and Bosley, 1988; Thayer, 1988; Wolsink, 1987). These studies focused on issues such as the lack of support among key stakeholders, reluctance among policy makers to dedicate themselves to consistent and effective policies, and the lack of understanding of the roots of public attitudes towards wind power schemes, in particular the underrating of the crucial significance of landscape issues in the attitude towards wind power schemes. Furthermore, questions about the social foundations of renewables in relation to the scale of the installations and the options for ownership of installations and of decentralized power supply were raised (McDaniel, 1983; Wolsink, 1987).

Nevertheless, the issue of social acceptance remained largely neglected in the 1990s, because of a high level of general public support for renewable energy technologies. However, as the papers in this issue demonstrate in more detail, there is more than one aspect of social acceptance that must be taken into account. There are a number of features of renewable energy innovation that bring new aspects to the debate on social acceptance. For one, renewable energy plants tend to be smaller-scale than conventional power plants, increasing the number of siting decisions that need to be taken. In some cases, such as micro-generation in residential buildings, the siting decision becomes in effect an individual investment decision. Secondly, as renewable energy conversion tends to be characterized by lower energy densities, the relative visual impact (per MWh of output) tends to be higher. This is partly reinforced by the fact that resource extraction in the case of fossil or nuclear energy happens below the earth's surface (Sieferle, 1982) and is thus invisible for everyday life of a citizen, while wind turbines and other renewable plants harness energy in a more visible way. It also means that renewable energy conversion tends to happen closer to where the energy consumer lives (the "backyard"), thereby increasing its visibility and bringing the environmental impact closer to their residence. Thirdly, given the ubiquitous presence of externalities in the energy sector, most renewable energy technologies do not compete with incumbent technologies on a level playing field, thereby making acceptance of them a choice between short-term costs and long-term benefits.

The set of papers on the social acceptance of renewable energy innovation presented in this issue provides both new conceptual contributions as well as in-depth empirical data analysis based on a variety of research methods and data sources from around the world. Particular cases are provided for Australia, Mexico, Japan, France and Germany. Several of the papers also review experiences in a number of countries including the UK, Germany, Denmark, Spain, Sweden, Greece, Italy, and the Netherlands. The special issue also reviews experiences with a number of renewable energy technologies. Most of the papers deal with issues particular to wind power, but three in particular have considered social acceptance issues with regard to small-scale energy systems, such as renewablesbased micro-generation, renewable fuelwood-based cooking-technologies, and solar water heaters. For comparison, one paper looks at social acceptance of an energy technology innovation related to fossil fuels, namely carbon capture and storage (CCS).

\section{Conceptualizing social acceptance}

Social acceptance is an often used term in the practical policy literature, but clear definitions are rarely given. We intend to contribute to the clarity of understanding by distinguishing three dimensions of social acceptance, namely socio-political acceptance, community acceptance and market acceptance. All three, sometimes interdependent categories of social acceptance are studied in this special issue (Fig. 1).

\subsection{Socio-political acceptance}

Socio-political acceptance is social acceptance on the broadest, most general level. Both policies (such as ecological tax-reform, see Energy Policy special issue 2006) and technologies can be subject to societal acceptance

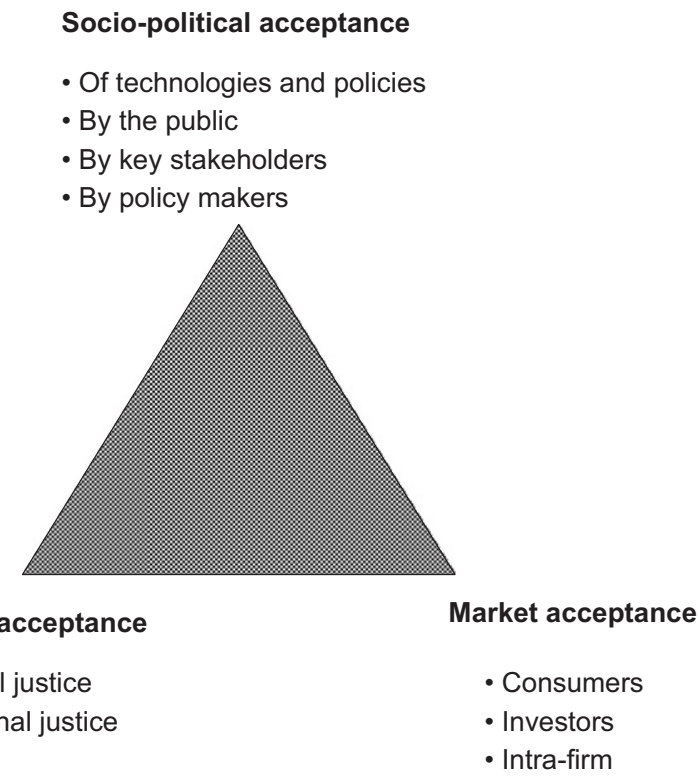

Fig. 1. The triangle of social acceptance of renewable energy innovation. 
(or lack thereof). Several indicators demonstrate that public acceptance for renewable energy technologies and policies is high in many countries. This is shown in opinion polls where broad majorities of people tend to agree with the idea of public support for renewables, even in countries where the government does relatively little to support them (Eurobarometer, 2003; BPA, 2003; Simon and Wüstenhagen, 2006). This positive overall picture for renewable energy has (mis)led policy makers to believe that social acceptance is not an issue. However, moving from global to local, and from general support for technologies and policies to effective positive investment and siting decisions, one has to acknowledge that there is indeed a problem (Bell et al., 2005). And whereas implementation rates ultimately are an aggregate of the number of successful cases, the striking fact is that there are huge differences in rates among countries that cannot be explained by the differences in wind resources (Toke et al., 2008).

Many of the barriers for achieving successful projects at the implementation level can be considered as a manifestation of lack of social acceptance. At the general level of socio-political acceptance this also concerns the acceptance by key stakeholders and policy actors of effective policies. Those policies require the institutionalization of frameworks that effectively foster and enhance market and community acceptance, for example establishment of reliable financial procurement systems that create options for new investors, and spatial planning systems that stimulate collaborative decision making.

\subsection{Community acceptance}

One area where academic research has recognized this early on is the second dimension of social acceptance of renewable energy innovation, namely community acceptance. Community acceptance refers to the specific acceptance of siting decisions and renewable energy projects by local stakeholders, particularly residents and local authorities. This is the arena where the debate around NIMBYism unfolds, where some argue that the difference between general acceptance and then resistance to specific projects can be explained by the fact that people support renewable energy as long as it is not in their own backyard, while others argue that this is at least an over-simplification of people's actual motives (e.g. Wolsink, 2006; Bell et al., 2005). Yet others have found evidence for exactly the opposite effect, namely that opposition decreases, rather than increases with the degree of being directly affected by a specific wind power project (Simon and Wüstenhagen, 2006). A particular feature of community acceptance is that it has a time dimension. As Wolsink (2007) in this issue demonstrates, the typical pattern of local acceptance before, during, and after a project follows a U-curve, going from high acceptance to (relatively) low acceptance during the siting phase (usually still positive on average) and back up to a higher level of acceptance once a project is up and running.
In this issue, we intend to shed some new light on factors influencing community acceptance, for example by highlighting the relative importance of factors related to distributional justice (How are costs and benefits shared?), procedural justice (Is there a fair decision making process giving all relevant stakeholders an opportunity to participate? (Gross, 2007, this issue), and does the local community trust the information and the intentions of the investors and actors from outside the community (Huijts et al., 2007, this issue).

\subsection{Market acceptance}

Finally, particularly as we move along from wind energy to smaller-scale renewables, another aspect becomes evident, which is that social acceptance can also be interpreted as market acceptance, or the process of market adoption of an innovation. In this perspective, we can learn from the literature on diffusion of innovation (Rogers, 1995), which explains the adoption of innovative products by consumers through a communication process between individual adopters and their environment. While energy technologies continue to be bound to infrastructures that make them inherently more complex for diffusion of innovation than other products, using the insights from this literature can be helpful to study market acceptance of technologies like micro cogeneration, solar thermal collectors and other energy technologies on the building level. The emergence of green power marketing (Bird et al., 2002; Wüstenhagen et al., 2003), where residents (including tenants) get the opportunity to "switch" to renewable energy supply without being actually involved in the physical generation, is probably the area where market adoption can almost completely be isolated from the broader social acceptance picture, reducing barriers to diffusion. If consumers demand increasing amounts of green power, there still need to be siting processes for power plants to supply this demand, so we may just see the effect at a later point in time. However, rejection or acceptance of green power does not correlate with power facilities in the backyard (Ek, 2005). To some extent, the separation between (physical) supply and demand that's inherent in the concept of green power marketing (and trading) might even aggravate the problem of social acceptance - for example when there is a lot of demand in one country (such as the Netherlands) but not enough social acceptance to build the corresponding supply infrastructure. The social acceptance lens would call for some caution with regard to ideas of extensive international green power trade - it seems questionable whether residents of a country with large resources (e.g. Scotland in the case of wind power) would be willing to approve the use of their landscape for exports of green power when they are already uncertain about the benefits of doing so for their own electricity supply.

In a wider understanding of market acceptance, the focus is not just on consumers, but also on investors. One 
aspect is consumers as investors, as in the case of Japanese community wind power (Maruyama et al., 2007, this issue). Last but not least, there is also an issue of intra-firm acceptance of renewable energy innovation. Numerous examples show that large energy firms are subject to path dependencies when it comes to their investment behaviour (Hirsh, 1989). How social acceptance is constructed within these firms would be an issue well worth studying, e.g. based on a comparison of the significant differences in market entry speed of some of the large electric utilities (e.g. Enel vs. Vattenfall Europe) or power technology manufacturers (e.g. GE vs. Siemens) when it comes to becoming active players in renewable energy. This could well be linked to some of the research on cognitive barriers within firms with regard to taking up environmental and sustainability issues (e.g. Bansal and Roth, 2000). Another interesting aspect is how international companies act in different countries (e.g. the differences in attitudes towards wind energy between E.On UK and E.On Germany). Because many of these companies still own and manage significant parts of the grid, often still with regional monopolies, their position also affects the opportunities of other potential investors (Stern 2006, p. 355). Moreover, there is a link with socio-political acceptance, because these firms are influential stakeholders in the development of energy policies and they can use their influence in the crucial political decisions about the design of financial procurement systems and the access to the grid for other investors in renewable energy systems.

\section{This special issue of energy policy}

\subsection{The relevance of location and the politics of voiced opinions}

The fundamental issue in the application of renewable energy technologies is that most of them may be relatively small scale, but an investment and siting decision still affects a multitude of other stakeholders, as opposed to just one customer or one investor. Hence, the decision needs approval by several stakeholders, not only by the investor. Building a wind farm soon becomes a local political decision, because it affects the local community in several ways. For all actors involved in the decision making process the question of acceptability is at stake. This rapidly becomes complicated when these actors are not only the surrounding residents and the local civil society organisations, but also investors from abroad, large energy companies, and higher tiers of government. The social characteristics of the application of the new technology immediately become crucial. Who is the investor? Is it an outsider? Is the initiator an actor from within the community? Is the community invited to participate in the project? Does the local community have significant influence in the process? Is specific local, tacit knowledge used or is the community only expected to say "yes"? If locals can be involved in either the process or the investment, does this apply to all or not? Moreover, who decides about that?

These are questions not only relevant to wind farms. Even in the extreme case of micro generation (discussed by Sauter and Watson, 2007, this issue), where the siting decision becomes in effect an individual investment decision, market acceptance, community and socio-political acceptance may still play a role for a number of reasons (affected neighbours, recommendations by architects and installers, local building codes, etc.). If a local government, a project developer, and a power company try to implement a residential solar power system by siting photovoltaic modules on rooftops in a new housing district, many crucial questions emerge that affect the acceptance of several actors. Who owns the modules: the homeowner, the landlord, the municipality, or the power company? Do the residents still have control over the roof of their home? On which houses are those units placed, and on which ones not? In other words, who is 'forced' to accept a unit, and on the other hand, who may feel 'excluded'? In what way do the PV-units affect the lives of surrounding residents, for example regarding the visual aspect or the constraints to planting trees because these may eventually shadow the modules?

All these questions become relevant in cases of implementation decisions, but they are of a fairly abstract nature when we look at the general level of the acceptance of wind and solar power technologies. This is largely overlooked by people who assume that a high general popularity of a new energy technology should be a strong precursor for acceptance of a specific project. Two of the papers in this issue address in particular the "not-in-myback-yard' (NIMBY) bias that hampers the vision of planners, investors and policy-makers (Wolsink, 2006). The NIMBY idea suggests that people have positive attitudes towards something (e.g. wind power) until they are actually confronted with it, at which point they oppose it for selfish reasons (O'Hare, 1977). However, Maarten Wolsink's paper shows that in the Netherlands' national Wadden Vereniging survey, the support or rejection of wind turbines in the Wadden region was not in any way related to the distance. Although there are always two sides in these conflicts, research has focused almost exclusively on the nimby side; however, analysing only the attitudes of opponents and ignoring those of supporters in the disputes tells only half the story. Meanwhile, the dominance of the characteristics of the landscape in the decision to support or reject on-land wind power schemes can be easily illustrated with figures (Table 1 of Wolsink, 2007, this issue), with regard to the huge differences in acceptability of wind turbines in different types of landscapes. The acceptability of wind power off-shore cannot be taken for granted either, but far from the coast other impact characteristics become dominant, such as impact on marine life (Firestone and Kempton, 2007).

Dan van der Horst's paper (Van der Horst, 2007, this issue) lexplains the importance of six 'variables' that can 
hamper the comparison between different public perception studies, and offers two broad conclusions. He argues that on aggregate, proximity does have strong influence on public attitudes to proposed projects, but the nature, strength and spatial scale of this effect may vary according to local context and 'value' of the land. Residents of stigmatised places are more likely to welcome facilities that are relatively 'green', while people who derive a more positive sense of identity from particular rural landscapes are likely to resist such potential developments, especially if they also live there. Secondly, the fear of being branded a NIMBY, and the positive ethics associated with the notion of renewable are both likely to 'colour' the responses of many interviewees. He argues that these aspects need to be clarified and accounted for in analyses of elicited responses if we are to improve our understanding of the social construction of individual attitudes in siting conflicts.

Arthur Jobert et al. (2007, this issue) also deal with the factors which are important for the acceptance of wind energy on the local level. Their paper reviews experiences regarding planned or existing wind energy parks on the basis of five case studies in France and Germany. The hypothesis is that two kinds of factors are decisive for the development of wind energy: on one hand, the framework conditions such as economic incentives and regulations; on the other hand, local and territorial factors, such as features of the local economy, the territory, local actors and the concrete planning process on-site. Therefore, Jobert et al. show how local acceptance is influenced by both planning rules and local factors. In general, the scale of wind energy projects and the dominant significance of the landscape qualities of the site require decision making that fully recognises the importance of local factors by adopting a collaborative approach to siting. This is also revealed in two other papers, one that focuses on issues of perceived (in) justice in the decision making process, and one on the role of trust in decision making.

\subsection{Community perspectives on fairness and trust}

Also in this issue, the importance of fair processes with regard to community acceptance is highlighted. Catherine Gross (2007, this issue) describes a community fairness framework which has potential application in community consultation to increase social acceptance of the outcome. This framework has been developed based on the findings from a wind farm pilot study in Australia where community perceptions of a consultation process are explored using procedural justice principles to evaluate fairness. A key research finding is that different sections of a community are likely to be influenced by different aspects of justice, namely by outcome fairness, outcome favourability and process fairness. In her paper, she explains that outcomes that are perceived to be unfair can result in protests, damaged relationships and divided communities particularly when decisions are made which benefit some sections of the community at the perceived expense of others.
An important element of perceived process fairness and damaged relationships is trust. Trust is a key issue in all facility siting issues. Siting decisions are always heavily loaded with risk components: environmental, economic, and social risks. The perceived fairness is to a large extent dependant on how potential risks are defined, how information about those risks is produced, and how and by whom they are managed (Owens, 2004). In particular, when investors and facility owners are community outsiders, trust in their aims, attitude and competence becomes an issue. The openness of the process for local involvement and the flexibility and open mind of the actors from outside are crucial, because things can easily go wrong. Risk research has revealed the 'asymmetry principle', which tells us that trust is fragile, as it is typically created slowly but can be destroyed rapidly (Slovic, 1993). Nicole Huijts et al. (2007, this issue) show empirical evidence on the role of trust. They also extend the range of articles on social acceptance of renewable energy innovation to a new technology that is related to fossil power generation: carbon capture and storage (CCS). Based on two surveys, they distinguish between the views of citizens and the views of professionally involved actors, such as government, industry and NGOs. They conclude that professional actors are following an in-depth evaluation process, including discussions in multi-actor working groups, and ending in a rather pro-CCS position. Their survey among citizens living near a potential storage site, on the other hand, reveals that public attitudes in general were slightly positive, but attitudes towards storage nearby were slightly negative. The general public appeared to have little knowledge about $\mathrm{CO}_{2}$-storage, and - surprisingly - to have little desire for more information. Huijts et al. conclude that under these circumstances, trust in the professional actors is particularly important. NGOs were found to be trusted most, and industry least by the general public. Trust in each of the three actors appeared to depend on perceived competence and intentions, which in turn were found to be related to perceived similarity of goals and thinking between trustee and trustor.

\subsection{Wind power: socio-political acceptance}

Fertile conditions for investments in renewable energy installations and for collaborative and fair decision making are to a large extent a result of institutional frameworks created at the national level. For example, the application of wind energy is governmental policy, and in most countries (Spain being a notable exception, where the decision is made at the regional level; Toke et al., 2008) changing a zoning scheme is a local political decision. The planning systems in countries are very different, but at the level of central government in several countries there is a tendency towards a growing top-down, technocratic, hierarchical way of thinking about how the planning systems must be shaped (Wolsink, 2003; Cowell and Owens, 2006). There is some doubt about the ability of 
this approach to support the creation of good conditions for acceptance and trust at the local level, particularly with regard to project developers from outside the community.

A clear example of the significance of the planning system is discussed by Alain Nadaï (2007, this issue) who reviews the policy framework in France which has triggered the takeoff of wind power capacity. A key element is that administrative decisions concerning the authorization of new wind power developments have been transferred at the level of department prefects (subdivision of the regions) and municipalities by the new law. The question remains open whether or not the new policy scheme might provide the right balance between territorial planning and room for open participation. The paper examines this development in the light of two key dimensions and concepts related to wind power policy: "planning" and "siting". They argue that planning and siting have different logics, which might make them complementary or contradictory. Whereas local acceptance refers to issues and processes related to siting, policy design tends to emphasize planning issues, leaving implicit the assumption that planning tools might solve siting issues. The French policy outcome, termed "flexible decentralized planning", is interesting in that it develops interfaces between planning tools and siting institutions. It is ambiguous in that final decision-power is left in stateplanners' hands, making it unpredictable the extent to which room will genuinely be provided for siting processes to take place.

The French case is interesting, because the implementation of wind power capacity has taken off only recently and the national political framework is highly centralized compared to other countries. An international comparison is made by Sylvia Breukers and Maarten Wolsink (2007, this issue) who compare diverging achievements in wind power implementation in the Netherlands, England, and the German state of North Rhine Westphalia, and address the extent to which wind power has become embedded in existing routines and practices of society with focused attention on the conditions that affect the local planning contexts. Local social acceptance has been shown to be problematic at this level. Together with the crucial significance of local involvement in siting decisions for the relative success in implementation, the authors recommend facilitating local ownership and institutionalising participation in project planning to help arrive at a better recognition and involvement of the multiple interests (environmental, economic and landscape) that are relevant at the local level of implementation.

The possibilities for community involvement in investments in wind power are also described by Maruyama et al. (2007, this volume). They describe the Japanese choice for a Renewable Portfolio Standard (RPS) that lacked an ambitious target for new renewable energy capacity. The introduction of a grid-opening feed-in system had been opposed by key actors, such as the Ministry of Economy, Trade and Industry and the power companies.
This is an example of how resistance to the introduction of effective support systems reveals a lack of socio-political acceptance that may hamper successful implementation. Furthermore, the importance of clear and consistent choices for a stable financial support system that guarantees access to the grid for all interested investors is also emphasised by Breukers and Wolsink (2007, this issue). It is not only the design of the support system, but also the stability and the reliability from an investors' perspective (yet another dimension of 'trust') that has shown to be important for successful implementation. Do potential investors trust authorities that they sustain their financial support instruments? In other words, do they trust the real commitment to the renewable energy policies of their policy makers that is still essential in market acceptance of renewable energy?

\subsection{Market acceptance: the deployment of micro- generation}

The empirical analysis of Maruyama et al. (2007, this issue) describes the emergence of community wind power in Japan. It provides interesting insights into investor behaviour. They show that taking the idea of participatory planning a step further towards financial participation of a group of retail investors can help to increase social acceptance. They also highlight important differences between the motivations of investors in a local versus a national community wind power fund, which makes their paper also an interesting contribution to the discussion about sustainable consumption and production. There is also the general question of acceptance of renewable energy innovation in the larger financial community, which deserves further academic attention.

Raphael Sauter and Jim Watson (2007, this issue) explain that social acceptance of renewable energy innovation has often been discussed in the context of large renewable technology projects, acceptance having been seen as rather passive consent by the public. However, they argue that the potential importance of micro-generation technologies in the future energy supply mix and policymakers' increasing attention to these technologies requires a different approach to the social acceptance of renewable energy innovation and energy infrastructure technologies. Instead of mere consent to an infrastructure project, domestic micro-generation requires active acceptance by homeowners, whereby individual households become part of the electricity supply infrastructure. Acceptance may therefore be expressed in various forms: attitudes, behaviour and-most importantly-investments. Sauter and Watson argue that different deployment models with varying degrees of company and consumer involvement will have a significant influence on the social acceptance of domestic micro generation and therefore the market uptake of these technologies. Three deployment models are elaborated in their paper, encompassing different roles for consumers and for energy companies, and reflecting 
possible changes in the electricity system. The models explored range from active consumer involvement to a more passive approach, and from company driven deployment to deployment in which companies provide back-up supplies of electricity to micro-generators.

\subsection{Social acceptance of renewable energy innovation in the south}

Finally, two papers in this issue discuss the issue of social acceptance of renewable energy innovation in a developing country context. Alexandra Mallett looks at the role of technology cooperation in technology adoption for solar water heaters, while Karin Troncoso et al. focus on the adoption of clean biomass technology in rural Mexico. Both of these papers contribute to further understanding of the elements required to succeed in meeting global sustainable development objectives via the use of renewable energy technological innovations.

\subsubsection{The role of technology cooperation}

Similar to Sauter and Watson's contribution on microgeneration in this issue, Alexandra Mallett (2007, this issue) discusses the need for more "active" social acceptance, within the technology adoption model by Rogers (1995) which claims that adoption comes about through a decision-making process occurring in stages - knowledge, persuasion, implementation and confirmation and can be traced to a number of factors such as relative advantage, complexity, and triability. She discusses how this model can be modified using an "active" definition of social acceptance. This paper argues that while Rogers' technology adoption model is a useful tool to explain social acceptance, this approach needs to be revised to reflect adequately on the effects of technology cooperation, an integral part of technology adoption. Using mainly qualitative analytical techniques, she obtained empirical evidence with regard to technology cooperation, in particular, from the experiences of those involved in solar water heaters in Mexico City (e.g. technicians, industry representatives, local government officials, community representatives/end users). The paper asserts that those forms of technology cooperation in which active participants are from various sectors and interact continuously throughout the process is most effective in eliciting social acceptance of renewable energy innovations.

\subsubsection{Social perceptions about technological innovation}

Karin Troncoso, et al. look at improved cook-stoves, which both reduce fuel consumption and address the health effects of indoor air pollution. The authors explain that different demographic and socio-economic factors have been analyzed to explain the low rates of success of these cook-stoves internationally, but there are almost no studies that examine the problem from the perspective of users. The aim of the study was to understand the factors involved when a user chooses among different cooking technologies. Through a qualitative methodological approach, they documented the adoption of the new technology through the implementation program of a Mexican local NGO. Results showed that although the NGO project has raised public awareness and women recognize the health problems associated with indoor air pollution, the improved stoves have not reached the poorest sector of the population. The differences among individual users were more significant than the differences found between communities with access to fuel-wood, pointing to further research opportunities with regard to effective customer segmentation strategies.

\section{Further research on social acceptance of renewable energy innovation}

In general, this special issue is meant to lay the foundation for a conceptual integration of research findings from different social science disciplines on social acceptance of renewable energy innovation. However, we are at an early point of maturity in this emerging field, so formulation of new relevant and rigorous research questions is urgently needed.

- As for socio-political acceptance,

$\bigcirc$ One of the key challenges is to bridge the nationallocal divide.

How to translate national policy objectives into locally accepted policies (and finally citing decisions). How to handle national-local conflicts (the German planning regulation for wind being an example, whose transferability to different regulatory environments needs to be looked at in more detail).

How to translate local initiatives into more ambitious and supportive policies, or how to create policy frameworks that tend to foster local project initiatives instead of overruling them.

- Another key challenge is gathering a critical mass of acceptance in the political system to introduce effective renewable energy policies. A few experiences point to the challenge of overcoming pressure and institutional settings which favour the application of less stringent or less dependable (for investors) market-based policies to promote renewable energy technologies, such as more recently in Japan (Maruyama et al., 2007, this issue). Recent studies also question the cost-effectiveness of the UK's quota system, where large incumbent energy suppliers influence market developments and the utilityrelated wind developers have an advantage over independent generators (Breukers and Wolsink, 2007, this issue).

It is also relevant to combine work on socio-political acceptance with work on market acceptance. For example, gaining investor acceptance for renewable energy policies is key if these policies are to result in effective market growth. 
- As for community acceptance, examples of relevant research questions that should be addressed include:

$\bigcirc$ How do international learning processes between opponents (or proponents) in different countries unfold (e.g. Swiss activists learning lessons from effective wind power opposition in Germany)?

$\bigcirc$ Some evidence seems to indicate that planners and investors from outside the community are facing more difficulties in finding social acceptance for wind energy projects than "locals". Therefore, further research could investigate the link between ownership and community acceptance, both in a more narrow sense of legal ownership, but also with regard to determinants of a (more subjectively defined) "sense of ownership".

$\bigcirc$ The crucial factor for acceptance of on-land wind power schemes is the perception of landscape amenity, but this factor is complex and not yet fully understood. Meanwhile, what are the crucial factors in acceptance of PV-modules, solar power plants, offshore wind power, biogas installations, biomass power plants, and biofuel production facilities?

$\bigcirc$ Given the strong focus of some of the renewable energy policies on developing countries, more research on social acceptance and adoption of renewable energy innovation in the South, especially among the poorest of people, should be an obvious priority area for further research. The two papers in this issue (Mallett, 2007; Troncoso et al., 2007) provide a good starting point.

- As for market acceptance, this is probably the most under-researched angle of this field, so far. Examples of relevant research questions that should be addressed include:

$\bigcirc$ How do intermediaries (such as architects, installers) influence the market acceptance of micro-generation?

o Customer segmentation: How can the Japanese example of investors in community wind power (Maruyama et al., 2007, this issue) be transferred to other countries and other renewable energy technologies? What is it that really makes people buy renewable energy, and how does this key motivation differ between customer segments?

$\bigcirc$ The theme of intra-firm acceptance provides rich research opportunities. Further work in this area could enhance our understanding of the current rethinking process in large energy companies towards taking a more or less proactive approach to renewables.

$\bigcirc$ Finally, factors determining acceptance of renewable energy innovation in the financial community should also be explored. For example, various actors in the financial community, such as private equity fund managers, pension funds, etc., could be surveyed with regard to the acceptance (and perceived effectiveness) of sustainable energy policies.

- In terms of methodologies, there is a point for more longitudinal research. In addition, qualitative case studies could be complemented by experimental research.

\section{Acknowledgements}

The authors acknowledge the financial support of the Swiss National Science Foundation (contract number 10CO12-111508/1), the Swiss Federal Office of Energy (contract number 151764) and BKW-FMB Energie AG for the organisation of the international research workshop "Social Acceptance of Renewable Energy Innovation" in Tramelan (Switzerland) on February 16-18, 2006. They also wish to thank their fellow members of the workshop's scientific committee, namely Markus Geissmann, Robert Horbaty, Tetsunari Iida, Maya Jegen, Milind Kandlikar, Cees Midden, Tim O'Riordan, Barbara Praetorius, Petra Schweizer-Ries, Carmen Tanner, Bernhard Truffer, and Heikki Willstedt Mesa, for their help in the review process.

\section{References}

Bansal, P., Roth, K., 2000. Why companies go green: a model of ecological responsiveness. Academy of Management Journal 43 (4), 717-736.

Bell, D., Gray, T., Haggett, C., 2005. The 'Social Gap' in wind farm citing decisions: explanations and policy responses. Environmental Politics 14, 460-477.

Bird, L., Wüstenhagen, R., Aabakken, J., 2002. A review of international green power markets: recent experience, trends, and market drivers. Renewable and Sustainable Energy Reviews 6 (6), 513-536.

BPA, 2003. (German Federal Public Relations Office) Bewertung der Struktur der Energieversorgung-Ergebnisse einer Repräsentativbefragung, Institut für Demoskopie Allensbach, 〈http://www.bmu.de/ files/meinungen_energiepolitik_031100.pdf $>$

Bosley, P., Bosley, K., 1988. Public acceptability of California's wind energy developments: three studies. Wind Engineering 12 (5), 311-318.

Breukers, S., Wolsink, M., 2007. Wind power implementation in changing institutional landscapes: An international comparison. Energy Policy 35 (5), in press doi:10.1016/j.enpol.2006.12.004.

Carlman, I., 1982. Wind energy potential in Sweden: the importance of non-technical factors. In: Fourth International Symposium on Wind Energy Systems. September 21-24, 1982, Stockholm, pp. 335-348.

Carlman, I., 1984. The views of politicians and decision-makers on planning for the use of wind power in Sweden. In: European Wind Energy Conference, 22-36 October 1984, Hamburg, pp. 339-343.

Cowell, R., Owens, S., 2006. Governing space: planning reform and the politics of sustainability. Environment and Planning $\mathrm{C}-$ Government and Policy 24 (3), 403-421.

Ek, K., 2005. Public and private attitudes towards "green" electricity: the case of Swedish wind power. Energy Policy 33, 1677-1689.

Eurobarometer, 2003. Energy: issues, options and technologies, science and society. A report produced by The European Opinion Research Group (EORG) for the Directorate-General for Research, Luxembourg.

Firestone, J., Kempton, W., 2007. Public opinion about large offshore wind power: underlying factors. Energy Policy 35, 584-598.

Gross, C., 2007. Community perspectives of wind energy in Australia. The application of a justice and community fairness framework to increase social acceptance. Energy Policy 35 (5), in press. doi:10.1016/ j.enpol.2006.12.013.

Hirsh, R.F., 1989. Technology and Transformation in the American Electric Utility Industry. Cambridge University Press, Cambridge MA. 
Huijts, N.M.A., Midden, C.J.H , Meijnders, A.L, 2007. Public acceptance of carbon dioxide storage. Energy Policy 35 (5), in press. doi:10.1016/ j.enpol.2006.12.007.

Jobert, A., Laborgne, P., Mimler, S., 2007. Local acceptance of wind energy. Factors of success identified in French and German case studies. Energy Policy 35 (5), in press. doi:10.1016/j.enpol.2006.12.005.

Mallett, A., 2007. Social acceptance of renewable energy innovations: the role of technology cooperation in urban Mexico. Energy Policy 35 (5), in press, doi:10.1016/j.enpol.2006.12.008.

Maruyama, Y., Nishikido, M., Iida, T., 2007. Wind power and society interaction in Japan: along the rise of community wind power. Energy Policy 35 (5), in press. doi:10.1016/j.enpol.2006.12.010.

McDaniel, B.A., 1983. Economic and social foundations of solar energy. Environmental Ethics 5 (2), 155-168.

Nadaï, A., 2007. "Planning", "siting" and the local acceptance of wind power: Some Lessons from the French case. Energy Policy 35 (5), in press. doi:10.1016/j.enpol.2006.12.003.

O'Hare, M., 1977. "Not on MY block you don't": facility siting and the strategic importance of compensation. Public Policy 25, 407-458.

Owens, S., 2004. Siting, sustainable development and social priorities. Journal of Risk Research 7, 101-114.

Rogers, E.M., 1995. Diffusion of Innovations, fourth ed. The Free Press, New York.

Sauter, R., Watson, J., 2007. Strategies for the deployment of micro generation: implications for social acceptance. Energy Policy 35 (5), in press. doi:10.1016/j.enpol.2006.12.006.

Sieferle, R. P., 1982. Der unterirdische Wald: Energiekrise und industrielle Revolution. München: Beck.

Slovic, P., 1993. Perceived risk, trust and democracy. Risk Analysis 13, 675-682.

Simon, A., Wüstenhagen, R., 2006. Factors influencing the acceptance of wind energy in Switzerland, poster presented at the workshop "Social acceptance of renewable energy innovation", Tramelan (Switzerland), 2006. 〈http://www.iwoe.unisg.ch/energy $\rangle$.
Stern, N., 2006. stern review on the economics of climate change, : accelerating technological innovation. Report to the UK Prime Minister and the Chancellor of the Exchequer, chapter $16<\mathrm{http} / /$ www.hm-treasury.gov.uk/media/9A3/57/Ch_16_accelerating_technological_innovation.pdf $>$.

Toke, D., Breukers, S., Wolsink, M., 2008. Wind power deployment outcomes: how can we account for the differences? Renewable and Sustainable energy Reviews 12, in press. doi:10.1016/j.rser. 2006.10.021.

Thayer, R.L., 1988. The aesthetics of wind energy in the United States: case studies in public perception. European Community Wind Energy Conference, Herning, DK, June 6-8. pp.470-476.

Troncoso, K., Castillo, A., Masera, O., Merino, L., 2007. Social perceptions about a technological innovation for fuelwood cookingcase study in rural Mexico. Energy Policy 35 (5), in press. doi:10.1016/ j.enpol.2006.12.011.

Van der Horst, D., 2007. Nimby or not? Exploring the relevance of location and the politics of voiced opinions in renewable energy siting controversies. Energy Policy 35 (5), in press. doi:10.1016/j.enpol. 2006.12.012.

Wolsink, M., 1987. Wind power for the electricity supply of houses. Netherlands Journal of Housing and Environmental Research 2 (3), 195-214.

Wolsink, M., 2003. Reshaping the Dutch planning system: a learning process? Environment and Planning A 35, 705-723.

Wolsink, M., 2006. Invalid theory impedes our understanding: a critique on the persistence of the language of NIMBY. Transactions of the Institute of British Geographers 31, 85-91.

Wolsink, M., 2007. Planning of renewables schemes. Deliberative and fair decision-making on landscape issues instead of reproachful accusations of non-cooperation. Energy Policy 35 (5), in press. doi:10.1016/ j.enpol.2006.12.002.

Wüstenhagen, R., Markard, J., Truffer, B., 2003. Diffusion of green power products in Switzerland. Energy Policy 31, 621-632. 